\title{
INFLUENCE OF THE NATURE OF ORGANIC ADDITIVES ON THE RATE OF CHEMICAL DEPOSITION OF NICKEL
}

\author{
Yulia AVERINA ${ }^{1}$, Yuri KAPUSTIN², Dmitriy ZHUKOV , Denis ZHIRUHIN ${ }^{4}$, Tigran VAGRAMYAN ${ }^{5}$ \\ MUCTR - D.Mendeleev University of Chemical Technoly of Russia, Moscow, Russian Federation \\ 19averinajm@mail.ru, ${ }^{2 k}$ ap@muctr.ru, ${ }^{3}$ Dzhukov35@yandex.ru, ${ }^{4}$ Zhir Den Alex@mail.ru, \\ 5Vagramyan@muctr.ru
}

https://doi.org/10.37904/metal.2019.905

\begin{abstract}
The influence of the nature of organic additives on the rate of low-temperature chemical deposition of nickel is studied. The class of organic compounds allowing to obtain adhesion coating of chemical nickel was revealed. The temperature ranges of the process are determined. The regularities of temperature influence on the rate of chemical deposition and the quality of the deposited coating are obtained. Mechanical tests were carried out on the samples obtained by this method.
\end{abstract}

Keywords: Corrosion protection, chemical deposition of nickel, organic additives

\section{INTRODUCTION}

The development of an electrochemical current generator on solid oxide fuel cells (SOFC) is one of the most urgent problems of power engineering. To test the electrochemical characteristics of single planar metal supporting SOFCs on a hydrogen-nitrogen mixture and syngas, and to test short-term life characteristics of the electrochemical characteristics of single planar metal supporting SOFCs, it is important to have high-quality equipment with high durability. The method of chemical nickel plating can be used to protect the tooling. In this paper, we will consider the option of obtaining a nickel coating that has the necessary properties for SOFC, which are the main element of the urban utility electric truck KAMAZ.

All recommended electrolytes of chemical nickel plating contain various components, which reflects the diversity and complexity of the processes occurring on the catalytic surface and in the electrolyte volume. In addition to the salt of nickel and the reducing agent - hypophosphite - the solution contains ligands that bind nickel ions into the complex, buffering additives, stabilizers and activators. When choosing the composition of the solution for chemical nickel plating, it is necessary to take into account the physicochemical features of the processes taking place.

Chemical precipitation of nickel alloys is possible in a wide $\mathrm{pH}$ range: from 3 to 6 for simple electrolytes and from 5 to 9 for alkaline complex electrolytes. To maintain the $\mathrm{pH}$, and as ligands, organic acids are most often used. The deposition rate and the quality of the coating obtained, as well as the stability of the solution of chemical nickel plating, will be determined by the presence of various functional groups in organic acids, buffering intervals and the stability of the complexes [1]. The purpose of this work is to study the effect of various functional groups of organic acids on the deposition rate of the coating, its appearance and performance characteristics.

\section{EXPERIMENTAL MATERIALS}

For the study, a working solution of the following composition was used $\mathrm{g} / \mathrm{I}:\left[\mathrm{NiSO}_{4} \cdot 7 \mathrm{H}_{2} \mathrm{O}-36 \mathrm{~g}\right.$

$\left.\mathrm{NaH}_{2} \mathrm{PO}_{2} \cdot \mathrm{H}_{2} \mathrm{O}-25 \mathrm{~g} ; \mathrm{CH}_{3} \mathrm{COONa}-25 \mathrm{~g}\right] ; \mathrm{C}_{3} \mathrm{H}_{6} \mathrm{O}_{3}(80 \%)-40 \mathrm{ml} / \mathrm{l}$.

Organic acids from the group of aminocarboxylic, aminophosphoric, sulfoamic, including aromatic compounds were introduced into this solution. 
The coating was besieged on rectangular samples of steel grade DC01. Preliminary preparation of the substrate surface was to degrease with a washing alkaline solution, decapitate in hydrochloric acid (1: 1) for 30 seconds. The coating was deposited for 30 minutes.

The thickness of the chemically deposited coating was determined by gravimetric method. Weighing was carried out on an analytical balance of the brand GR-200 (A \& D, Japan), the measurement accuracy was $0.0001 \mathrm{~g}$.

Thickness was calculated by the formula:

$\delta=\frac{\Delta m \times 10^{4}}{S \times \rho}, \mu m$

where $\Delta m$ - weight gain, g; $\quad S$ - surface to be coated, $\mathrm{cm}^{2} ; \quad \rho$ - the density of the coating,

$\rho=8 \mathrm{~g} / \mathrm{cm}^{3}$ [2].

According to the already known thickness of the coating, the deposition rate was calculated by the following formula:

$V=\frac{\delta \times 60}{\tau}, \frac{\mu m}{h}$

where $\delta$ - coating thickness, $\mu m ; \tau$ - the duration of the process, min [2].

The gloss of the coatings was measured using Elcometer 480 gloss meter. The device records the intensity of the reflected light and converts it into units of glass according to the special Glass Unit (GU) scale. A value of $0 \mathrm{GU}$ corresponded to a matte surface with zero reflection, and a value of $100 \mathrm{GU}$ corresponds to a shiny surface. A surface area was examined with the OLYMPUS LEXT-OSL 4100 laser confocal microscope with MPLAPONLEXT 10 (x216) and MPLAPONLEXT 50 (x1069) objectives. The phase composition of the precipitated coating was obtained on XRF EDX-7000

\section{EXPERIMENTAL}

The following kinetically dependencies of the sedimentation rate on the required parameters were obtained for the test solution. The dependence of the deposition rate of the coating on the temperature of the working solution is presented in Table 1.

Table 1 Dependence of the deposition rate of nickel coating on the solution temperature at specific load $0.75 \mathrm{dm}^{2} / /$ at $\mathrm{pH} 6$

\begin{tabular}{|c|c|}
\hline $\begin{array}{c}\text { Temperature } \\
\left({ }^{\circ} \mathrm{C}\right)\end{array}$ & $\begin{array}{c}\text { Deposition rate } \\
(\boldsymbol{\mu m} / \mathbf{h})\end{array}$ \\
\hline 50 & 2 \\
\hline 55 & 6 \\
\hline 60 & 10 \\
\hline 75 & 15 \\
\hline 80 & 20 \\
\hline
\end{tabular}

With an increase in temperature, the process of chemical precipitation of nickel is accelerated; however, solutions operating at temperatures below $70^{\circ} \mathrm{C}$ are of the greatest interest for production. This is due to the fact that at lower temperatures better-quality compact precipitates with a high phosphorus content are formed. In addition, the solutions do not contain ammonia and are more resistant to self-decomposition [1]. As the working temperature was chosen $60^{\circ} \mathrm{C}$. 
Figure 1 shows the dependence of the deposition rate of a nickel coating on the specific load of the deposited surface at various concentrations of nickel ions in solution

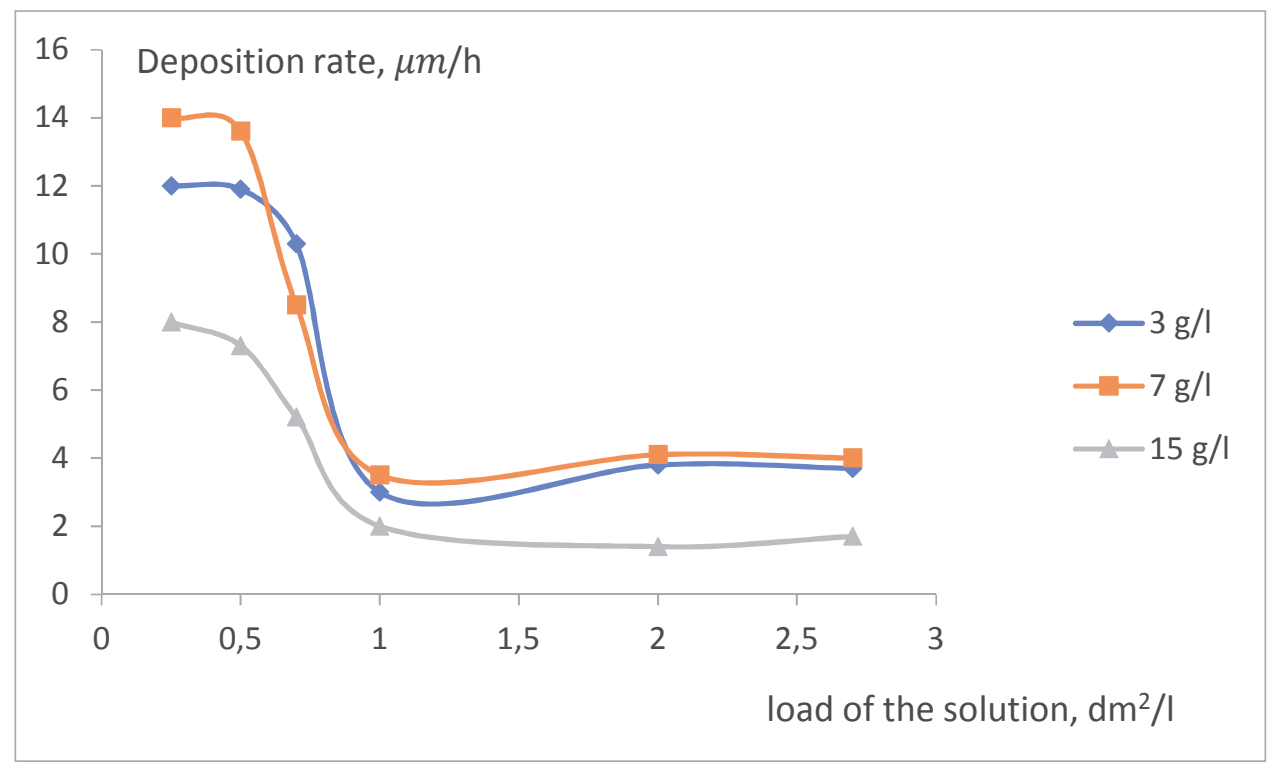

Figure 1 Dependence of the deposition rate of the coating on the specific load of the solution, temperature $60^{\circ} \mathrm{C}, \mathrm{pH} 6$

As the optimum, a specific load of $0,75 \mathrm{dm}^{2} / /$ was chosen, and to maintain a high deposition rate, a concentration of $7 \mathrm{~g} / \mathrm{l}$. The results of the deposition rate of the nickel coating from the $\mathrm{pH}$ of the solution are shown in Table 2.

Table 2 Dependence of the deposition rate of nickel coating on the solution $\mathrm{pH}$ at a specific load of $0.75 \mathrm{dm}^{2} / /$, $\mathrm{pH} 6$

\begin{tabular}{|c|c|}
\hline $\mathbf{p H}$ & Deposition rate $(\boldsymbol{\mu m} / \mathrm{h})$ \\
\hline 5.0 & 5.0 \\
\hline 5.5 & 9.4 \\
\hline 6.0 & 10.0 \\
\hline 6.5 & 11.0 \\
\hline 7.0 & 9.5 \\
\hline
\end{tabular}

It is seen that the maximum rate of chemical precipitation of nickel is observed at $\mathrm{pH} \mathrm{6.5.} \mathrm{However,} \mathrm{as} \mathrm{the}$ process of chemical nickel plating proceeds, the $\mathrm{pH}$ of the working solution decreases and the deposition rate decreases, and the phosphorus content in the coating increases, which has a positive effect on its corrosion resistance. Therefore, the optimum value of $\mathrm{pH} 6$.

During the chemical deposition of nickel, one of the important criteria for its corrosion resistance is the concentration of phosphorus in the coating. The concentration of phosphorus affects the structure of the coating, the porosity and appearance of the sediments. The optimum concentration is $7-10 \%$ by weight. In this form compact and amorphous coatings with high corrosion resistance.

The concentration of phosphorus in the deposited nickel coating with the given parameters was determined by removing the X-ray fluorescence spectrum. 


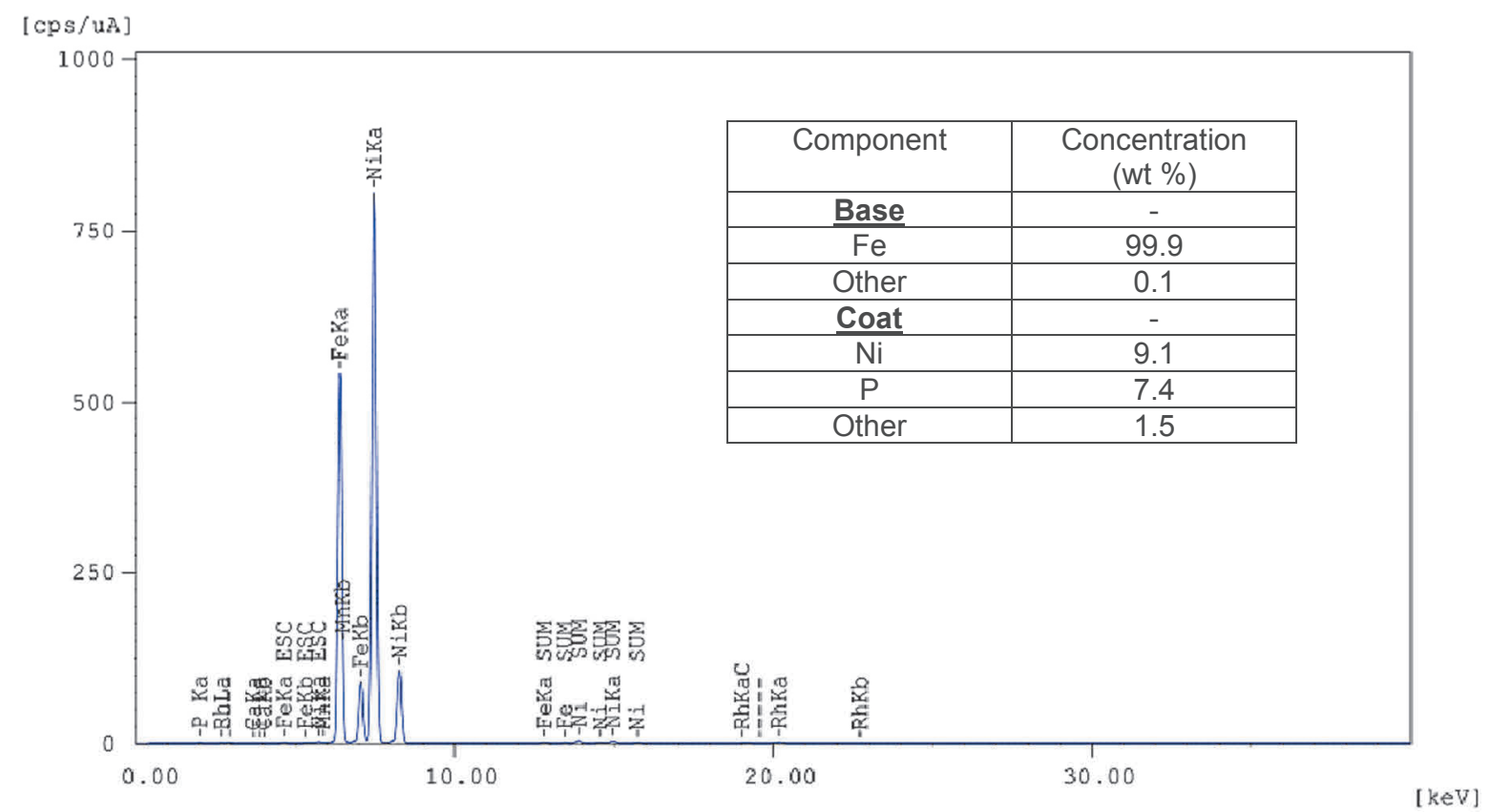

Figure $2 \mathrm{XRF}$ of nickel coating deposited on a steel base, from the working solution at a deposition temperature of $60^{\circ} \mathrm{C}$, specific load $0.75 \mathrm{dm}^{2} / 1, \mathrm{pH} 6$

Table 3 Dependence of the deposition rate of the nickel coating from the working solution on the concentration of hydroxycarboxylic acids. (At a deposition temperature of $60^{\circ} \mathrm{C}$, a specific load of $0.75 \mathrm{dm}^{2} /$ )

\begin{tabular}{|c|c|c|c|}
\hline Substance & $\begin{array}{c}\text { Concentaration } \\
(\mathbf{g} / \mathbf{l})\end{array}$ & $\begin{array}{c}\text { Dep.rate } \\
(\boldsymbol{\mu} \mathbf{m} / \mathbf{h})\end{array}$ & $\begin{array}{c}\text { Glass } \\
(\mathbf{G U})\end{array}$ \\
\hline Ascorbic acid & 1 & 10.3 & 75 \\
\hline Ascorbic acid & 5 & 14.7 & 89 \\
\hline Ascorbic acid & 10 & 14.0 & 100 \\
\hline Malic acid & 1 & 10.0 & 90 \\
\hline Malic acid & 5 & 7.3 & 93 \\
\hline Malic acid & 10 & 6.2 & 95 \\
\hline
\end{tabular}

When a chemical nickel plating of hydroxycarboxylic acids is introduced into the solution, an increase in the deposition rate of the coating is observed, probably due to an increase in the buffer capacity of the solution. The gloss of the coating also increases. It is known that hydroxycarboxylic acids increase the solubility of the reaction by-products (phosphates) of chemical nickel plating [1].

Table 4 Dependence of the deposition rate of nickel coating from the working solution on the concentration of aminocarboxylic acids. (At a deposition temperature of $60^{\circ} \mathrm{C}$, a specific load of $0.75 \mathrm{dm}^{2} /$ )

\begin{tabular}{|c|c|c|c|}
\hline Substance & $\begin{array}{c}\text { Concentaration } \\
(\mathbf{g} / \mathbf{l})\end{array}$ & $\begin{array}{c}\text { Dep.rate } \\
(\boldsymbol{\mu} / \mathbf{h})\end{array}$ & $\begin{array}{c}\text { Glass } \\
(\mathbf{G U})\end{array}$ \\
\hline Glycine & 1 & 4.4 & 83 \\
\hline Glycine & 5 & 7.2 & 90 \\
\hline Glycine & 10 & 6.0 & 78 \\
\hline EDTA & 1 & 8.0 & 80 \\
\hline EDTA & 5 & 6.0 & 82 \\
\hline EDTA & 10 & 4.2 & 80 \\
\hline
\end{tabular}


Aminocarboxylic acids form rather strong complexes with nickel $(\log \beta=19$ for glycinate, $\log \beta=15$ ethylenediaminetetraacetic acid), because of which the activity of nickel ions in solution decreases, which causes a decrease in the deposition rate of the coating. They also help to increase the solubility of phosphates.

Table 5 Dependence of the deposition rate of the nickel coating from the working solution on the concentration of aminophosphonic acids. (At a deposition temperature of $60^{\circ} \mathrm{C}$, a specific load $\left.0.75 \mathrm{dm}^{2} / \mathrm{l}\right)$

\begin{tabular}{|c|c|c|c|}
\hline Substance & $\begin{array}{c}\text { Concentaration } \\
(\mathbf{g} / \mathbf{l})\end{array}$ & $\begin{array}{c}\text { Dep.rate } \\
(\boldsymbol{\mu m} / \mathbf{h})\end{array}$ \\
\hline HEDPa & 5 & 8.0 & 70 \\
\hline HEDPa & 10 & 9.4 & 82 \\
\hline HEDPa & 20 & 11.0 & 80 \\
\hline HEDPa & 50 & 12.0 & 89 \\
\hline ATMPa & 5 & 10.3 & 90 \\
\hline ATMPa & 10 & 9.0 & 89 \\
\hline ATMPa & 20 & 11.0 & 92 \\
\hline ATMPa & 50 & 10.0 & 90 \\
\hline
\end{tabular}

Aminophosphoric acids form sufficiently strong complexes with nickel $(\log \beta=25$ for hydroxyethylenediphosphoric acid, $\log \beta=26$ for nitrilotrimethylenephosphoric acid, as a result of which nickel ion activity decreases significantly. However, as the experiments with ATMPa are performed, the formation precipitation at the bottom of the glasses, by chemical composition, these precipitations were identified as sodium and nickel phosphates.

Table 6 Dependence of the deposition rate of the nickel coating from the working solution on the concentration of sulfo and aminosulfonic acids. (At a deposition temperature of $60^{\circ} \mathrm{C}$, a specific load of $0.75 \mathrm{dm}^{2} / /$

\begin{tabular}{|c|c|c|c|}
\hline Substance & $\begin{array}{c}\text { Concentaration } \\
(\mathbf{g} / \mathbf{l})\end{array}$ & $\begin{array}{c}\text { Dep.rate } \\
(\boldsymbol{\mu m} / \mathbf{h})\end{array}$ & $\begin{array}{c}\text { Glass } \\
\text { (GU) }\end{array}$ \\
\hline Taurine & 5 & 8.3 & 85 \\
\hline Taurine & 10 & 9.0 & 80 \\
\hline Taurine & 15 & 9.0 & 79 \\
\hline Phenolsulfonic acid & 1 & 10.0 & 89 \\
\hline Phenolsulfonic acid & 5 & 9.1 & 96 \\
\hline Phenolsulfonic acid & 10 & 8.4 & 89 \\
\hline Alizarin Red C & 1 & 10.0 & 95 \\
\hline Alizarin Red C & 5 & 7.3 & \\
\hline
\end{tabular}

As can be seen from the above table, the introduction of a chemical nickel solution of aminosulfonic acid and aromatic sulfonic acids does not have a significant effect on the speed of the chemical nickel plating process, but significantly improves the appearance of the coating (Figure 3).

Mechanical adhesion tests have shown that the coating deposited from the working solution has a high degree of adhesion to the steel base. The adhesion value depends on the phosphorus content in the coating and at a concentration of $7-10$ mass \% coverage is the most compact. 


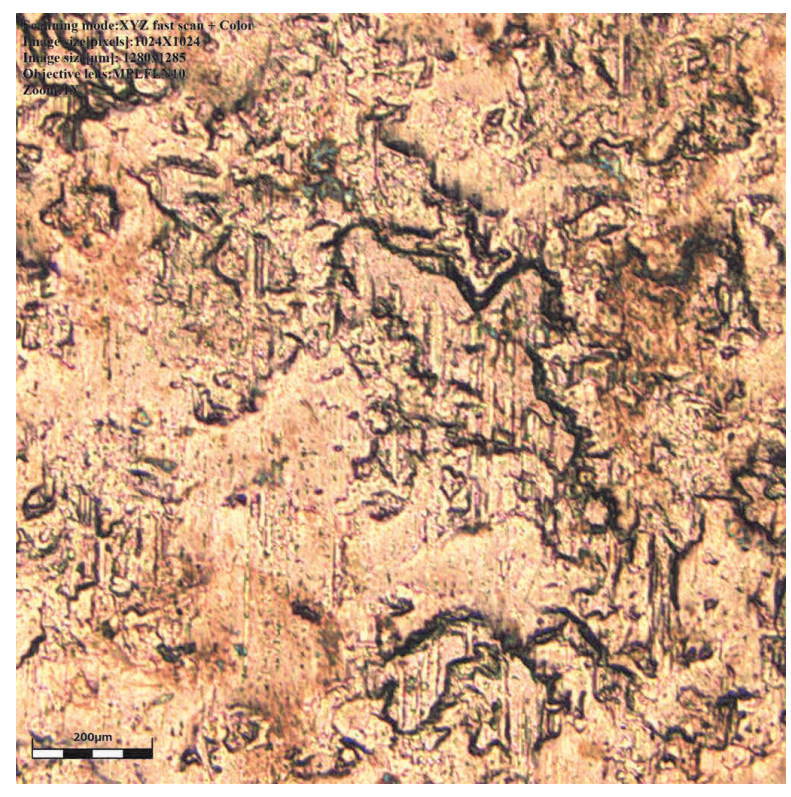

Figure 3 Microphotography of nickel coating, applied from the working solution, with optimal parameters with the addition of phenolsulfonic acid $5 \mathrm{~g} / \mathrm{l}$ on a steel base with an increase in X200

\section{CONCLUSIONS}

The influence of various functional groups of organic acids on the process of chemical nickel plating from lowtemperature solutions was investigated. The positive effect of oxycarboxylic acids on the deposition rate of nickel coating was revealed. Introduction to the composition of the solution of aromatic sulfonic acids has little effect on the speed of the process of chemical nickel plating, but change its appearance. Mechanical tests have shown that the adhesion value depends on the phosphorus content in the coating and organic acids introduced into the chemical nickel plating solution do not affect its value.

\section{ACKNOWLEDGEMENTS}

The work was done as part of an agreement between the MINISTRY OF EDUCATION AND SCIENCE OF THE RUSSIAN FEDERATION and Public Joint-Stock Company "KAMAZ" on the provision of subsidies from the federal budget for the implementation of a comprehensive project to create hightech production with the participation of MUCTR "№074-11-2018-008 of" June 5, 2018 and the contract between KAMAZ and the MUCTR-218-1 / 2017 for the implementation of research, development and technological works $(R \& D)$ on the topic: "Development and creation of high-tech production of urban municipal electric truck with expander and semi-autonomous vehicle control system" from 10.25.2017

\section{REFERENCES}

[1] V. D. SKOPINTSEV, E. G. VINOKUROV, "Theoretical and applied aspects of autocatalytic formation of coatings based on Nickel-phosphorus alloy", Moscow, VINITI ran: RHTU. Mendeleev, 2018. - 228 p.

[2] ISO 4527:2003, Metallic coatings - "Autocatalytic (electroless) nickel-phophorus alloy coatings" - Specification and test methods. 